\title{
Personnel Management Digital Model Based on the Social Profiles' Analysis
}

\author{
Sergey Barykin ${ }^{1} * \mathbb{C}^{0}$, Olga Kalinina ${ }^{1}$, Igor Aleksandrov ${ }^{1}$, Evgenii Konnikov ${ }^{2}$, \\ Vladimir Yadikin ${ }^{3, *}$ and Mikhail Draganov ${ }^{4}$ \\ 1 Graduate School of Service and Trade, Peter the Great St. Petersburg Polytechnic University, \\ Polytechnicheskaya, 29, 195251 St. Petersburg, Russia; olgakalinina@bk.ru (O.K.); a7830298@gmail.com (I.A.) \\ 2 Graduate School of Economics and Technologies, Peter the Great St. Petersburg Polytechnic University, \\ Polytechnicheskaya, 29, 195251 St. Petersburg, Russia; konnikov.evgeniy@gmail.com \\ 3 Laboratory «Advanced Production Technologies» of the National Technological Initiative Center, Peter the \\ Great St. Petersburg Polytechnic University, Polytechnicheskaya, 29, 195251 St. Petersburg, Russia \\ 4 Faculty “Computer Systems and Technologies”, Technical University of Sofia, 1000, 8 Kl. Ohridski Blvd, \\ 1756 Sofia, Bulgaria; mdraganov@tu-sofia.bg \\ * Correspondence: sbe@list.ru (S.B.); v.yadikin@gmail.com (V.Y.)
}

Received: 26 August 2020; Accepted: 14 November 2020; Published: 16 November 2020

\begin{abstract}
This paper examines a new approach to defining the task of personnel management in the digital age, taking into account the fundamental changes in internal communications stemming from an increasing use of digital platforms such as intranet, blogs, bulletin boards, instant messaging, and social networking sites. Personnel social media presence plays internal communication roles and thus relates to technologies of social profile analysis regarding employee interaction within the digital economy. The research aims at examining the task of personnel management based on data deriving from social media, for instance social networking sites and other social media tools, with the development of a relevant model for personnel management assessment. It could be shown that communication becomes one of the important aspects of personnel management, which consists of, i.e., human resources planning, recruitment, onboarding, assessment of individual work effects, as well as staff training, rewarding and motivating employees. Effective communication is a prerequisite for carrying out the above-mentioned tasks and performing work effectively. This means that the digital management of personnel can be viewed as a complex task, assuming that organizations operate less by using any formal connections and more by instilling in employees such feelings as feeling inspired, technologically advanced, and proud (on the basis of social media analytics). This paper presents theoretical foundations for developing a model for personnel management with consideration of the distinct employee features based on social media data and included in the assessment process. This allows the same approaches to be used for future research and modeling for assessing team effectiveness. In this paper, a methodological and instrumental solution to the current problem of creating the most effective work team in a digital ecosystem is proposed. The tools proposed to make it possible to create the most potentially effective work team based on the automated processing of natural information contained online on social profiles of potential members of the work team. At the same time, the level of communication compatibility acts as the criterion for the potential effectiveness of the work team. This is an innovative solution for the existing method of managing personnel.
\end{abstract}

Keywords: human resource management; digital personnel management; social media; employee interaction 


\section{Introduction}

This study focuses on personnel management in the context of digital transformation. The relevance of the study is that the topic is investigated in the context of the employment multiplier in high-tech industries in Europe. It shows that the appearance of one high-tech workplace leads to the emergence of an additional five low-tech jobs [1]. It can be concluded that the process of managing an organization's personnel within a digital ecosystem while maintaining basic goal setting is transformed from an instrumental point of view. Important features of digital platforms, such as the elimination of competition with the rise in collaboration, should not be put aside during the research. At the same time, the growth of employment in the high-tech sector in lagging regions, which depends on the growth of innovation, can be supported by increasing confidence in institutions and by improving social ties. The transition from the traditional system of personnel management to a digital one involves the difference between how the personnel interact with each other and with the management. The key factor in the digital system of interaction is the ability of each employee to freely access the information and analytical center. The digital system of interaction also differs from the traditional one in the expanding channels for exchanging information and analytics.

Considering the task of personnel management in the digital age, it could be shown that the problem of digital personnel management is the scientific search for features of employee interaction in the new technological structure of Industry 4.0 under the influence of a flow of innovations. These innovations are implemented on the basis of the process of labor automation, depending on the cognitive abilities of employees [2] aiming to extract economic benefits, in addition to reducing labor costs [3]. It includes increasing productivity, reliability, quality, and safety. The specific nature of work should be studied for the process of digital personnel management. The main features of labor automation and education could be specified as a result of the study of the impact of technology on the automation and replacement of labor [4]. It should be taken into account that in the context of digital transformation, the nature of work may not reflect a person's educational qualifications and may also depend on the ICT technologies present in the economy.

In this regard, the research gap could be identified as the problem of interaction between different categories of personnel, depending on the disposition to perceive digital transformations in the context of creating a digital personnel management system. The large body of data on employees requires the development of appropriate models that allow conclusions to be drawn about the assessment of employee interaction. The data from potential employees' social networks can be used as the basis for obtaining information about specific characteristics of personnel, allowing them to organize working teams for different tasks. The research question addressed in this paper relates to forming the system of digital personnel management being the object of the research. The paper covers the task of developing the analytics model of employees' social profiles aiming to improve the interaction between the workers. The authors consider the problem of digital personnel management based on social media data. Thus, the purpose of this work is to develop a model for evaluating staff interaction based on social media data to form a digital personnel management system.

\section{Literature Review}

In the concept of an on-demand economy [2], it is considered that the role of intermediaries that ensure the search for both highly qualified and low-skilled services is performed by platforms. Digitalization and the on-demand economy have an impact on the labor market and, in particular, change the process of labor organization. It also changes the roles of employers and employees, both in traditional enterprises and industries, and those involved as agents in the on-demand economy. A thorough forecast of future emerging and declining roles by region and country for the period from 2018 to 2022 was carried out by [5]. The research conducted by [6,7] illustrates the risk of job loss and the share of workers, which can be automated depending on the country. The work [7] argues that for developing countries with a high level of unemployment, the risk of automation is higher. Novakova [8] upholds this assertion with the statement that in "Anglo-Saxon, Nordic countries and 
the Netherlands jobs are less automatable compared to the Eastern and South European countries, Germany, Chile and Japan." According to [9], ICT's fragmentary nature influences employment in Russia. The work [10] also ascertains that digitalization mostly relates to low-skilled workers performing routine tasks. Contrary to the opinion that the loss of wages for low-skilled workers is the result of newcomers appearing and not salary reduction, [10] illustrates the rise in the USA of high and low education jobs for the period 1979-2012. The European Commission also claims about threats to routine and noncognitive jobs. The research [11] also ascertains a significant contribution to employment thanks to digitalization, which can be estimated at an aggregated global level with a $0.07 \%$ reduction in the unemployment rate for the period 2004-2015.

The common task of user interest profiling is considered in [12] for both personalized web search and recommendations as well as retrieval systems. The authors of this paper propose to obtain user interest profiles from a quiz game being incorporated with the Facebook online social network. In this game, the user is asked 10 questions from different categories with different difficulty levels. Therefore, both explicit Facebook profile and implicit quiz game profile features are extracted for each user.

One interesting approach is considered in a scientific publication by [13]. Fossen and Sorgner analyze the perception of various categories of personnel in the processes of digital transformation within the personnel management system. This approach explains why the authors organize professions into four groups, depending on the degree of substitution of personnel labor with digital technologies. In this paper, the following are highlighted: rising stars (staff can improve their skills), the territory of machines (professions whose routine operations can be automated), the territory of a person (professions that are not replaced by digital technologies), and dying professions (transformation without changing the essential content of operations). It could be shown that communication becomes one of the important aspects of personnel management, which consists of, i.e., human resources planning, recruitment, onboarding, assessment of individual work effects, as well as staff training, rewarding and motivating employees. Effective communication is a prerequisite for carrying out the above-mentioned tasks and performing work effectively.

It is important to identify the extent to which social media is currently used by organizations to improve the efficiency of personnel management. The effectiveness of the personnel management process is closely related to the extent to which employees share the organization's mission and perceive their work as a contribution to the implementation of this mission. One of the tasks of social media is to build a system of communication between employees being alternative to the traditional system of subordination.

Social media will be defined as computer technologies that facilitate the creation and exchange of information, emotions, ideas, career interests, and other forms of expression through virtual communities and networks. The work [14] considers the social network analysis as well as content analysis of corporate social responsibility (sustainability) reports in relation to sustainable human resource management, taking into account the employee training of a wide range of enterprises. Another field of social media analysis could include client relationship management (CRM) using social media platforms studied in [15].

From the personnel management point of view, social media can be useful even at the stage of finding and selecting personnel. By using social media tools, the employer can actively recruit potential candidates as well as verify them. Currently, HR branding is largely based on the use of social media resources.

Within an organization, social media has several goals:

(1) Introduce employees to each other (which is important in large international companies)

(2) Break down hierarchical boundaries;

(3) Create a community (team);

(4) Provide social tools for collaboration (creating, organizing, and discussing information within the company). 
The work [16] explains that one of the most important priorities is employee engagement. The second is a company's reputation, and the third is "building trust" with different types of audiences, such as employees, customers, stakeholders, and so on. The research also shows that the employees prefer to receive detailed information in writing to digest thoroughly enough. Likewise, some information can be collected easier and faster with the help of internal social media vehicles. It does not cancel the important role of face-to-face communications, which stay essential [17]. While interviewing the executives of Bosch, it was found that only one-third of them use the internal social media platform, and one-third, for example, do not have time for it. The work [18] determined that social media does not provide communication performance, but it is based, first and foremost, on social ties, shared vision, and social capital. The researchers [19] improved the understanding of social media "usefulness" for a company, in a context of "time-management, task performance and contextual performance." The research confirmed once again that the use of social media increases the performance of executives. Some papers, e.g., [20], IBM Institute for Business Value and IBM Smarter Workforce Institute analysis [21], insist on "active employee listening" and exchanging opinions, thus internal social media platforms such as Glassdoor, Vault, and Memo are options. The research showed that the younger the executives, the more they believe their voice will be heard and actions will be taken. The work [22] discusses the "experimental and ad hoc" nature of using social media in organizations, though not strategically planned. Omar showed the high importance of social media for knowledge sharing behavior in an organization [23]. The research [24] also confirmed the importance of the use of Enterprise 2.0 and revealed its strengths, like the "well-defined processes and standardized information flows." Accepting the effectiveness of social media in corporate interaction, the study [25] underlines the disadvantages of using social media, such as internet addiction and lack of concentration.

The example of China [26] highlights that vertical and horizontal communications are positively associated with using social media, also bearing in mind individual and team performance. The four-layer version of the CEF (communicative ecology framework) consists of the technological layer (social media), the discursive layer (the content of the communication), individuals as a separate layer, and the social environment. The researchers [27] noted the social media era's fundamental shift in internal communication upon the influence of digital platforms, blogs, messaging, and social networking sites.

The research of [28] on social media also prioritizes the relationships inside an enterprise and employee engagement. It also prescribes different types of media according to the goals of an enterprise [29], and while reviewing the information presented by social business enthusiasts, points out advantages such as bottom-up communication and the self-organizing of employees. The authors also found that team communication remains the most effective in its traditional face-to-face manner. Either way, a small portion of employees considered interactions over social media to be more effective. This portion is assumed to grow with time. For this reason, such research needs to be reconsidered regularly. Men shows the positive impact of using social media for internal interactions in an enterprise [27] and proves that employee evaluation of the quality of CEO communication directly influences the quality of employee-organization relationships. It can be seen that assertive CEO communication, characterized as dominant and competitive, may likewise have positive effects on the perceived quality of CEO communication.

The conclusion showing the importance of social media stipulates that assertive, competitive, dominant, and forceful CEO communication establishes the CEO as a strong, confident, and competent leader, therefore boosting the trust of employees in their leader and the organization, their willingness to be controlled, and possibly their commitment to and satisfaction with the organization. Thus, Men proved the following hypotheses:

(1) Regarding the positive impact on CEO communication quality from:

-H1) Responsive CEO communication;

-H2) Assertive CEO communication. 
(2) Regarding the positive impact on the quality of employee-organization relationships from:

-H3) Responsive CEO communication;

-H4) Assertive CEO communication.

(3) Regarding the positive impact on the quality of employee-organization relationships from CEO communication quality as a whole:

-H5) CEO communication quality positively influences the quality of employee-organization relationships.

At the same time, [30] found a positive impact on enterprise interactions on using non-work-related social media. The paper [31] points to the significant difference in using corporate blogging for star employees and low-performance employees.

In general, the main method to be used to estimate the role of social media is the in-depth interviewing of employees. It should be mentioned that since different researchers interviewed different enterprises, the effectiveness of only a number of social media can be seen. The assortment of social media used varies from one enterprise to another. It is also assumed that each country possesses its own preferred and more and less popular social media. Therefore, there is a gap in the research on the effectiveness of social media in Russia, for example, a very vast country and, like other countries, stands out in terms of its mentality. Moreover, there is another gap in the research of the effectiveness of social media in different types of enterprises, such as IT, heavy industry, or fashion, or medical clinics, etc., and small, medium, and big enterprises. Another point is that different interviews embrace different age groups, pointing out that the attitude of generations $X$ and $Y$ towards social media is more positive than older generations. The most popular social media was named by some research. It should be taken into account that with time their popularity will change, and thus, research in this sphere should also be conducted with regard to the specifics of the country.

\section{Materials and Methods}

In accordance with the conclusions made earlier, it can be concluded that the process of managing an organization's personnel within a digital ecosystem, while maintaining basic goal setting, is transformed from an instrumental point of view. At the same time, this transformation is differentiated according to the level of management. This differentiation appears in a nonuniform decrease in the labor intensity of this process as well as in the heterogeneous vector of the transformation itself. It is particularly advisable to preserve the management principles at the top-management level and only partially equip the managerial decision-making process with tools. Firstly, this fact is due to the high proportion of the expert component in the likelihood of an adopted management decision succeeding, which in turn is caused by the high cost of the consequences of inefficient management decisions. At the lowest level of management, the advisability of maximizing the equipping of the management decision-making process with tools is also impractical. This fact is due to the relatively insignificant cost of ineffective management decisions for an enterprise. Therefore, the most promising option for a digital transformation and equipping of the management decision-making process with tools is middle management. Likewise, it should be noted that how promising this transformation is grows exponentially for project work teams [32]. The universal objective is to create a temporary work team to carry out project activities that have a predictable and conditionally predictable result and a recognizable, limited duration. Such teams within the existing classical method of personnel management are formed according to the principle of regulatory replacement of employee competencies necessary for successfully realizing the project. According to this principle, this kind of temporary workgroup is formed according to professional competencies, which are necessary for successfully implementing the project and achieving the set result in the shortest or standard timeframe. However, such an approach does not involve taking into account the psychological, psychographic, social, spiritual, or other types of compatibility of the working group members. Certainly, an experienced and effective manager is able to consider these factors and form the best possible comparable team. However, these 
solutions, within the classic methodology of personnel management, are of an exclusively expert nature, which significantly increases the subjectivity of the decisions made and increases the value of a specific management representative for the company. In the authors' opinion, consideration of these factors can be systematically universalized and presented as a mathematical model.

Natural information generated by potential members of the team on social networks can serve as the information base of this model $([3,33,34])$. This choice is thanks to two features of this information:

(1) This information is generated by potential members of the team with no understanding of its possible use for analysis by third parties and for subsequent management decisions based on it. This fact determines its maximum objectivity.

(2) This information is publicly available and does not involve creating any additional complexity for forming it.

However, despite the unique positive features mentioned above, this information has one global drawback -it is presented in its natural form and, from the start, is not suitable for machine analysis or statistical processing [35]. This fact determines the need to first decode it and then analyze it. The universal research methodology for such information within the framework of the goal setting described earlier is shown in Figure 1.

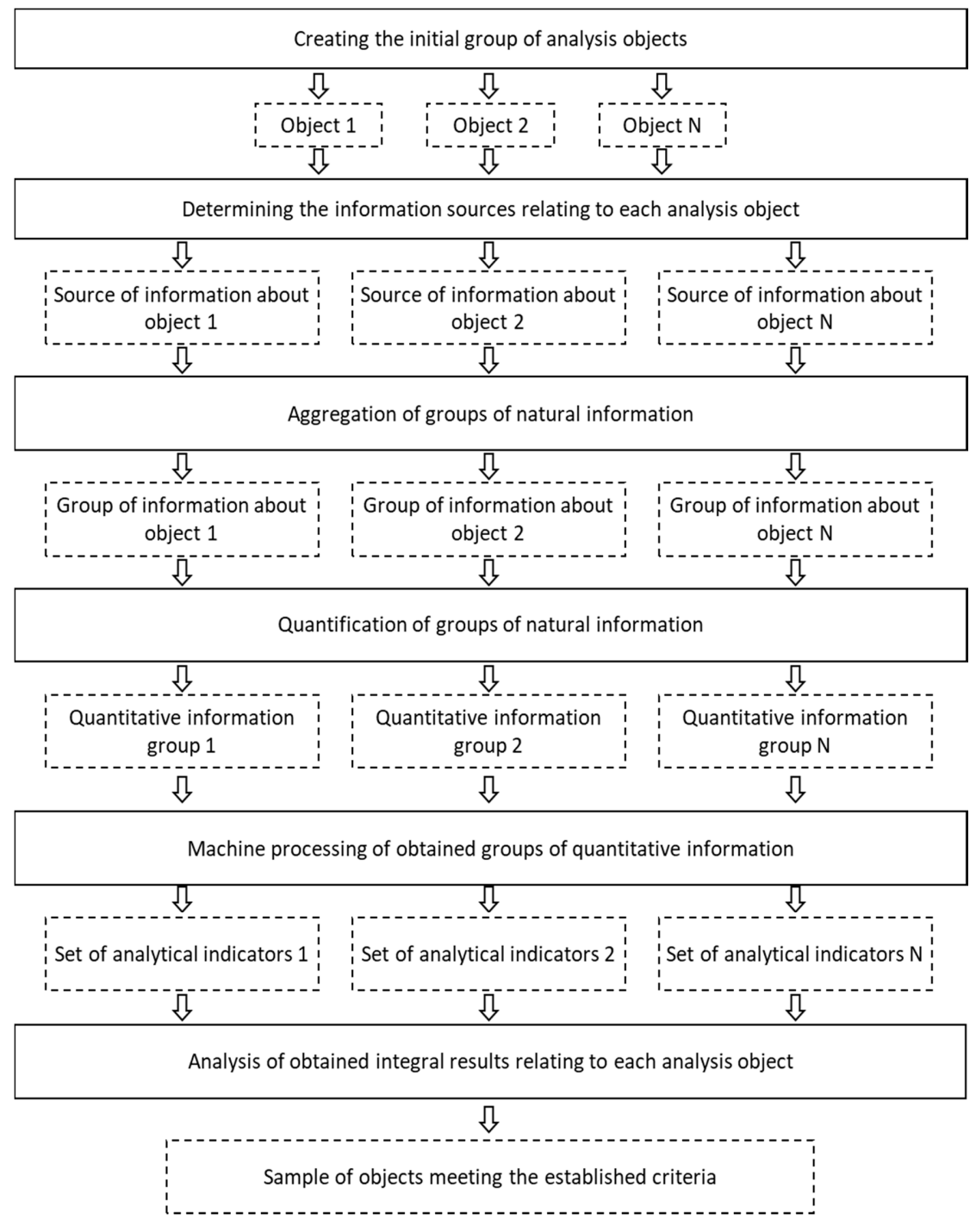

Figure 1. Universal method for processing natural information when solving problems of multiple choice of personnel. 
The method presented is universal in nature and can be applied when forming project workgroups. However, in one of the key properties of management decisions made in a digital ecosystem, there is a necessary consistency. The method described replaces parameters of professional competencies with other parameters of a social, psychological, and other nature, and the typical personnel information used is replaced with natural information $([36,37])$. However, this method is still qualitatively consistent with the classic methodology for managing personnel. The authors propose introducing a maximized criterion, according to which its systematic assessment is to be carried out. For this criterion, it is suggested that the parameter of work team compatibility be used.

Work team compatibility should be understood as the potential increment of the specifications for producing a beneficial result by communicative optimization. It should be assumed that the lack of communication barriers, as well as an optimal level of social, psychological, and other types of compatibility, allows the process of producing a beneficial result to be significantly sped up thanks to not needing to reform patterns of communication, as well as an overall emotional height. This hypothesis is the basis for developing the appropriate tools.

Thus, this compatibility is central to the result of forming an effective work team. The universal method presented above has been transformed according to introducing a single optimization criterion (Figure 2).

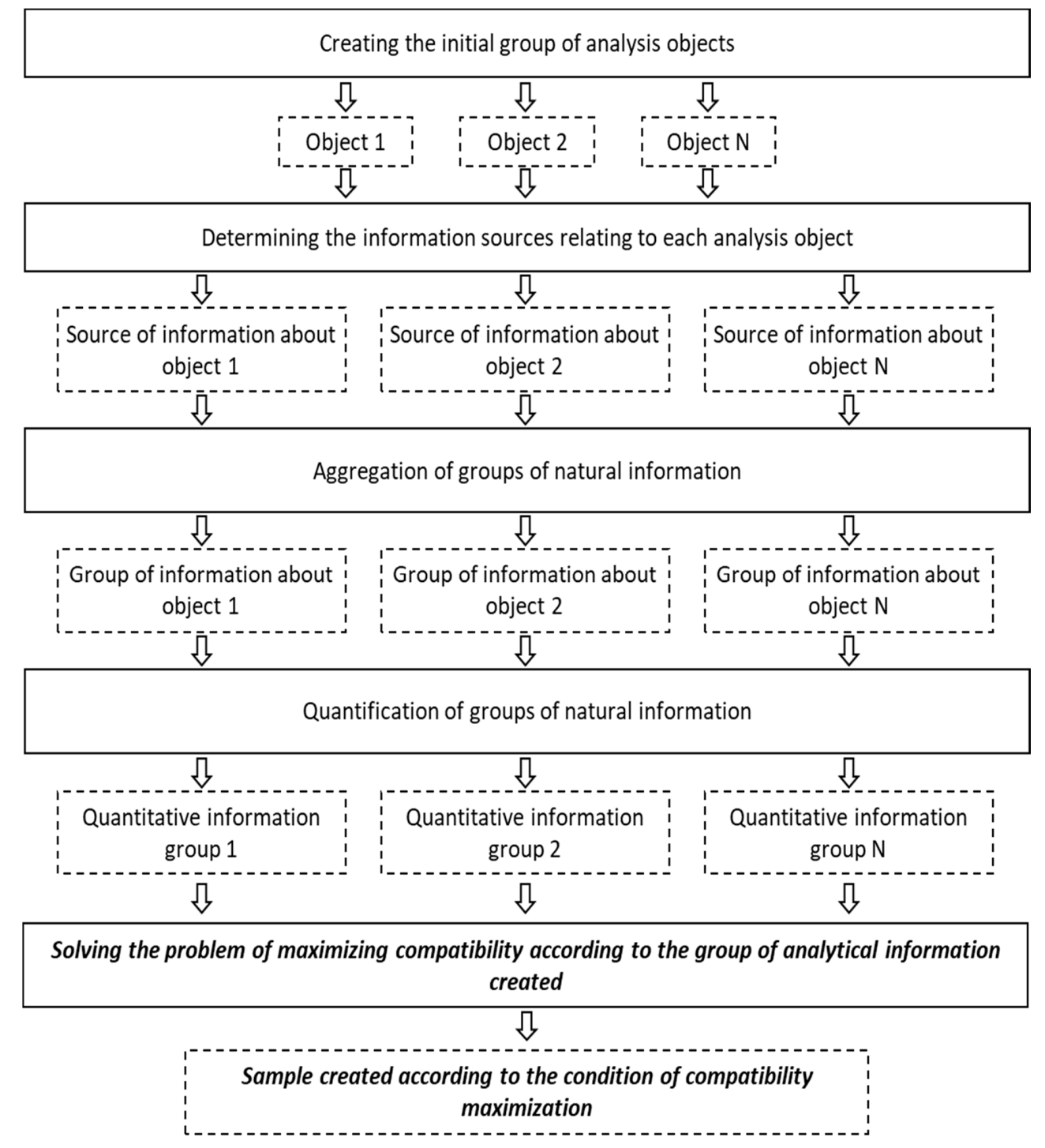

Figure 2. Method for forming the most compatible team based on processing natural information. 
Thus, equipping the personnel management decision-making process with tools within a digital ecosystem involves automating each stage of the method created. For the goals of this automation, it is most advisable to use the high-level programming language Python 3. This choice is due to its universality in solving each of the problems of the given method, which, in turn, provides a significant number of user-thread libraries, largely automating several intermediate and auxiliary algorithms.

\section{Results}

Below is a look at each of the stages given in the method described above. At the first stage, it is necessary to create an initial grouping of analysis objects. Within this research, the suggestion of limiting the general total number is put forward. It is suggested that the company limits their choice exclusively to their employees, while other personnel groups are limited by their maximum number. Thus, it is proposed for the first stage to initially include a limited number of potential members of the workgroup, selected by the classic method or created influenced by natural factors (such as the number of company personnel).

Within the second stage, it is suggested to determine the information sources relating to each object of the analysis. In fact, this stage involves choosing an appropriate social network. Since this research is carried out in the Russian Federation, it should be mentioned that the most popular social network in this country is vk.com. This social network is extremely popular in the CIS area, largely copying the functions of Facebook. Likewise, as with Facebook, this social network contains elements such as an "information thread," by which users are able to exchange public information as well as express their stance on some information by liking and reposting. User profiles of this social network contain information relating to their education, age, hobbies, as well as other demographic, geographic, and psychographic characteristics. However, unlike Facebook, vk.com has an open API, which significantly increases analytical possibilities. Thus, during this research, the method given is detailed for the social profiles of the analyzed objects in the social network vk.com.

During the third stage of the described method, natural information on the researched objects is aggregated. The amount and type of the researched information are limited by the contents of social profiles. Earlier in this article, a list of initial information contained on social user profiles was given. To determine the specific type of information, it is necessary to define the research characteristics. Firstly, the geographic and demographic information should be excluded, specifically: sex, age, place of birth, and so on. This exception is due to the low informative nature of the given data for purposes of forming limitations. The presence of communication barriers between the local people of various provinces or the people of different ages is unavoidable when dealing with unprofessional interaction. Since professional communication is assumed in a workgroup, it is necessary to determine the specifics, which can point to natural communication barriers within professional interaction. Likewise, it should be noted that taking into account demographic and geographic features implies many conditional exceptions, the consideration of which implies a significant complication of the method examined, or an integration of the expert assessment systems, which significantly increases the labor and cost of implementing the method. Therefore, it is necessary to identify the universal characteristics of the communication process. In the framework of this research, linguistics is used as the categorical basis for determining these characteristics since the source of any communication barriers occurring is in fact the communication process, the content of which is largely studied by linguistics. As the social network profiles of potential team members are serving as the information source, the field of linguistics can be limited exclusively to computational linguistics. The process itself of professional communication is an exchange of information coded in the natural information form and aimed at reaching a predetermined result. In summarized form, this information can be characterized by describing two basic components:

(1) Content component. This component characterizes the lexical content of relayed natural information. The description of this component implies not only the identification of key content lexemes and their frequency but noncontent lexemes as well. Furthermore, in an excerpt 
from professional communication, analysis of this component makes it possible to establish the area of interest of the research object.

(2) Emotional component. This component characterizes the emotional tone of the content component. In this case, the most effective tool for describing this component is to analyze tonality. Tonality is the emotional attitude of the author of the statement to some object and is expressed in the content component. Analyzing the tonality of the content component makes it possible to determine the attitude of the subject to a specific object, as well as the general communication patterns of the subjects.

Thus, the quantitative characteristics of the highlighted components act as the subject of the research. The object in this case can be exclusively the posts on the user page of a social profile. These posts can be generated by the users themselves and can also be reposts of other users. A hypothesis can be put forth on the tonal and content extrapolation of the communicative peculiarities of a user in this collection of content. Therefore, it is the user posts, aggregated into a uniform list, on social profiles that will result from the third stage of the method.

At the fourth stage of the method, the aggregated natural information is quantified. As noted earlier, the subject of the research is the tonal and content characteristics of the user posts on the analyzed social profiles. The tonal characteristics are looked at first. The tonality of the analyzed posts can be described by a number of features. In this case, to assess the tonality of the information of the environment, the open library for semantic analysis, using the language Python, was used- "Dostoevsky" (URL for library "Dostoevsky": https://github.com/bureaucratic-labs/dostoevsky). This library was created based on the database "RuSentiment dataset," and its accuracy according to criterion F1 is 0.71, which is a necessary and sufficient level of accuracy. This library helps reveal tonal features of a text such as the neutrality, passibility, negativity, positivity, and naturalness of language. Each of the characteristics given measure from 0 to 1 . In terms of the tools being created, three characteristics have the most significance:

Level of positivity of the post text (positive). This characteristic reflects the level of the positive emotional message present in the text.

Level of negativity of the post text (negative). This characteristic reflects the level of the negative emotional message present in the text.

Naturalness of post text (speech). This characteristic reflects the author of the text's tendency to use a natural (conversational) form of communicating.

By using the library Dostoevsky, these characteristics can be assessed for each of the user posts. However, the significance of the characteristics of the earliest posts is substantially lower than the characteristics of later posts. This fact is due to the ability of an individual to change their communication patterns. Therefore, the integral indicators of the tonal features of the analyzed users can be calculated using the following models:

$$
\begin{aligned}
T^{\text {positive }} & =\frac{\sum_{1}^{N} \frac{2 *(N-i+1)}{(N+1) * N} * t_{i}^{\text {positive }}}{N} \\
T^{\text {negative }} & =\frac{\sum_{1}^{N} \frac{2 *(N-i+1)}{(N+1) * N} * t_{i}^{\text {negative }}}{N} \\
T^{\text {speech }} & =\frac{\sum_{1}^{N} \frac{2 *(N-i+1)}{(N+1) * N} * t_{i}^{\text {speech }}}{N}
\end{aligned}
$$

where: $T^{\text {positive }}$ is the integral coefficient for the level of positivity in the distributed content; $T^{\text {negative }}$ is the integral coefficient for the level of negativity in the distributed content; $T^{\text {speech }}$ is the integral coefficient for the naturalness of the distributed content; $t_{i}$ positive is the level of positivity of $i$ post in the analyzed group; 
$t_{i}{ }^{\text {negativ }}$ is the level of negativity of $i$ post in the analyzed group;

$t_{i}$ speech is the level of naturalness of $i$ post in the analyzed group;

$N$ is the number of posts in the analyzed group;

$i$ is the ordinal number of analyzed posts in the group.

The given indicators can sufficiently characterize the tonal features of the type of communication most acceptable for the object analyzed. These indicators can be determined for each of the social profiles and in the future should go through analysis.

The content component, in turn, can be described firstly using the specifics and structure of the lexical array. Analysis of the content component, first of all, is aimed at determining the lexical elements, which are most often and popularly used by the researched object. The basic category of this kind of analysis can firstly be the lexeme, a word as an abstract unit of morphological analysis. The most commonly used lexemes (either word combinations or specific word forms) can be called tokens. For the key analytical tool, it is suggested in this case to use groups of tokens from social profiles. For the quantification criterion (criterion for the importance of a token), it is suggested to use the frequency of how often one token or another is used. The tokenization procedure of a text group is shown in Figure 3.

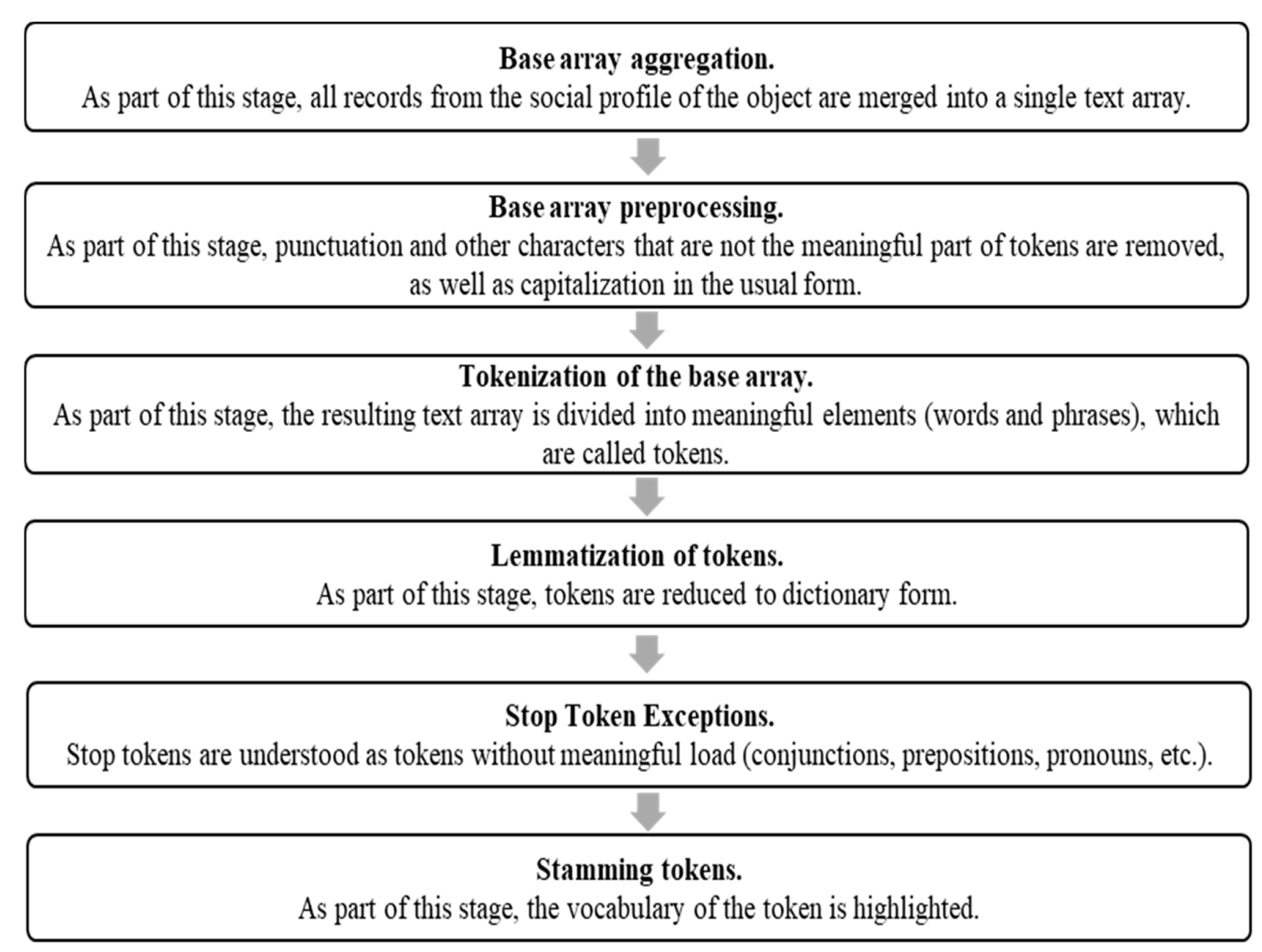

Figure 3. Algorithm for forming a group of tokens from a social profile.

The groups resulting from this algorithm are quantified by calculating how often each token is mentioned and are aggregated into a single analytical group. Thus, the objects within the created method are analyzed based on the highlighted tools for quantifying the content and emotional component of the groups of text information distributed by the analyzed objects. The created groups are the initial groups of quantitative information.

During the next stage of the method, the compatibility maximization is solved according to the initial groups of quantitative information created. According to the definition of work team compatibility highlighted above, the solution to this problem lies in the tools for finding optimal compatibility. The total number of objects existing within this problem can be separated into two sets: 
(1) $\mathrm{A}_{0}$-initial set, which includes all potential members of the workgroup;

(2) $A_{f}$-final set, which includes members of the workgroup most compatible with each other.

The optimization algorithm solves the problem of transitioning from set $\mathrm{A}_{0}$ to set $\mathrm{A}_{\mathrm{f}}$. At the same time, both sets need to be separated into a single number of professional roles, in each of which there can be put from 1 to $\mathrm{n}$ representatives. The transition from set $\mathrm{A}_{0}$ to set $\mathrm{A}_{\mathrm{f}}$ is examined according to professional roles (Figure 4).

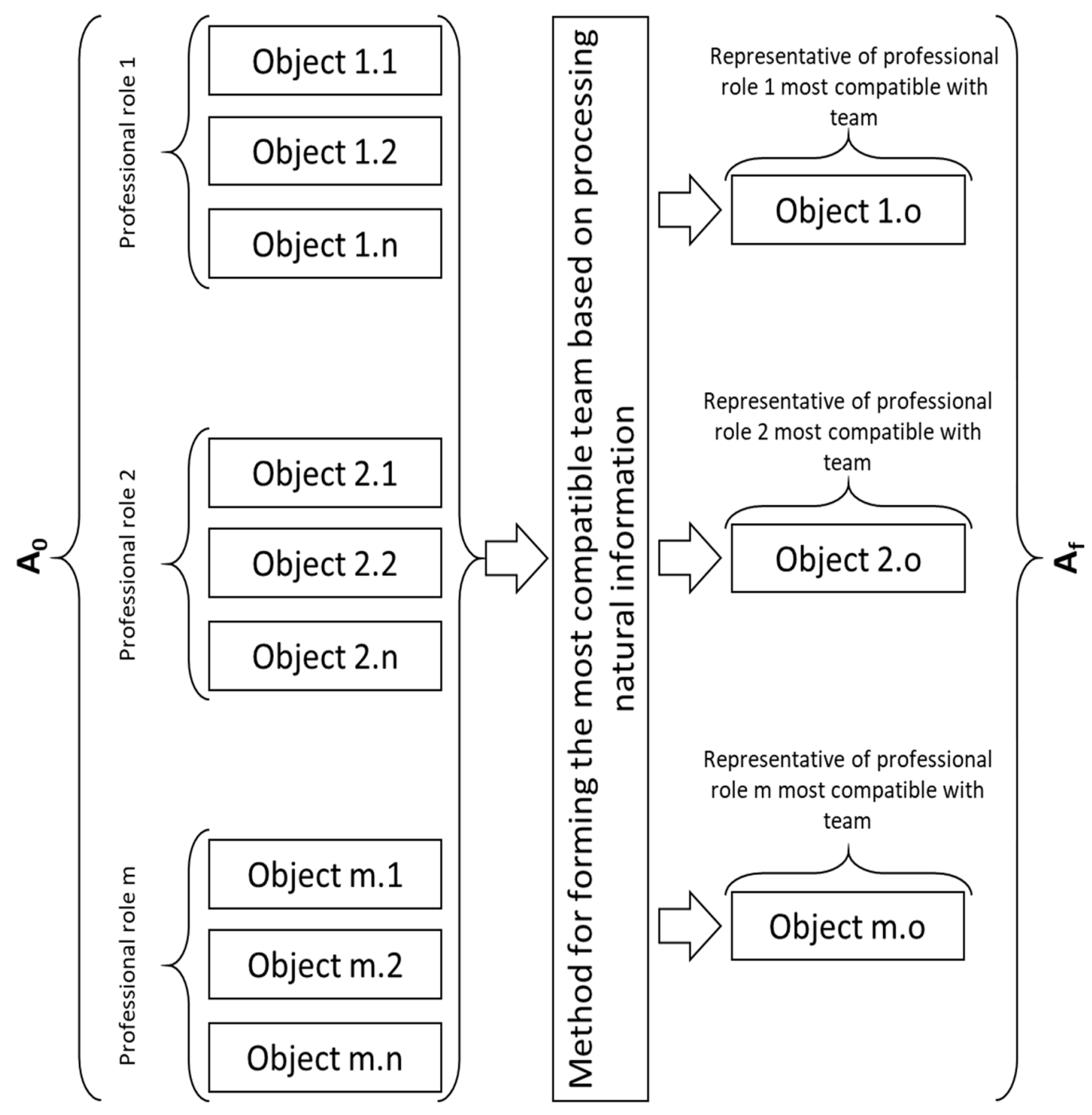

Figure 4. Technique for creating the most compatible team.

Based on the presented technique, it can be concluded that the resulting set $A_{f}$ is variable. Therefore, the initial stage of determining the most compatible team is to determine all potential combinations of this team. Next, a single comparative criterion needs to be introduced, which can be determined for each team, based on the specifics of the communication components described above. Likewise, unequivocal conclusions requiring no multidimensional processing should be formed on its comparison.

It should be noted that in this research, the specific weight of the influence of the emotional and content components on the compatibility indicator is the same. Therefore, the resulting criterion can be determined as the average value of these components. As a result, this criterion can initially be divided into two constituents, which are looked at individually. First, the emotional component is considered. To determine this component, three coefficients were proposed earlier, which reflect the 
tonal characteristics of the researched groups of text information distributed by the objects. Since each of the variants of a potentially compatible team contains a limited number of members, for each of which corresponding coefficients have been determined, the researcher can binarily match each of them. Communication in such a group cannot be initially limited by regulation, which implies the possibility of (or need for) each member to cooperate with the others. Therefore, by using tools of combinatorics, coefficient value pairs can be put together, which reflect the compatibility of the communicating objects (Figure 5).

$\mathbf{A}_{\mathrm{f}}$

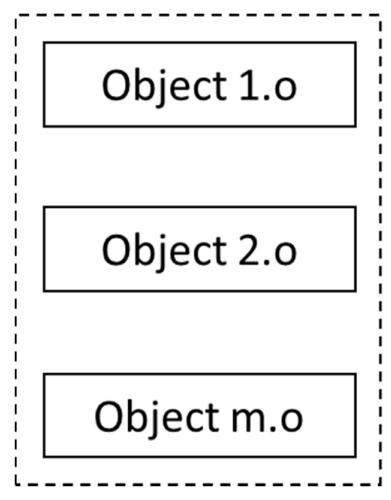

Possible binary communication combinations

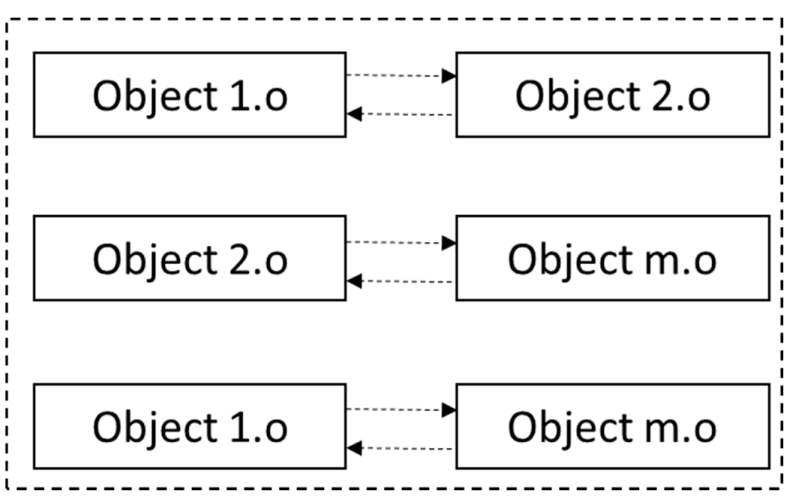

Figure 5. Technique for creating binary communication combinations.

The arrows in the field "possible binary communication combinations" reflect the direction of communication. The total corresponding coefficient values for the best possible number of binary communication combinations of objects form two comparable series of data (series $e$ and series $u$ ). The compatibility level of the team is determined by a degree of how similar these series are. One of the most effective parameters characterizing this parameter for two series of data is the Pearson correlation coefficient. Consequently, assuming that the specific weight of the three identified tonal characteristics is the same, the coefficient for the tonal compatibility of a work team can be determined in the following way:

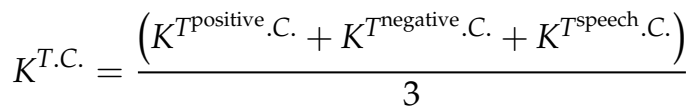

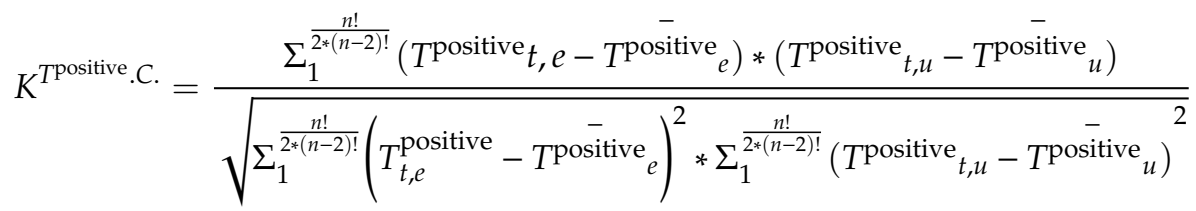

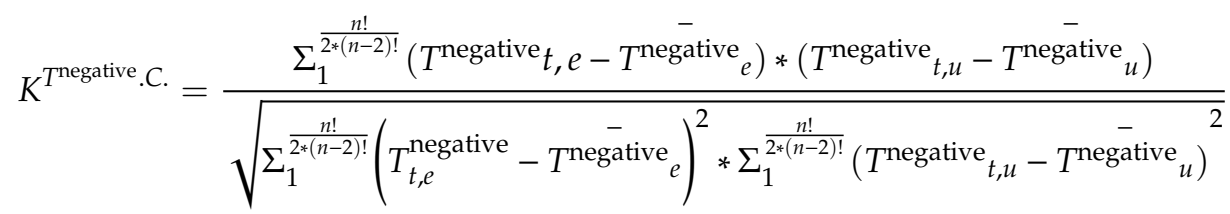

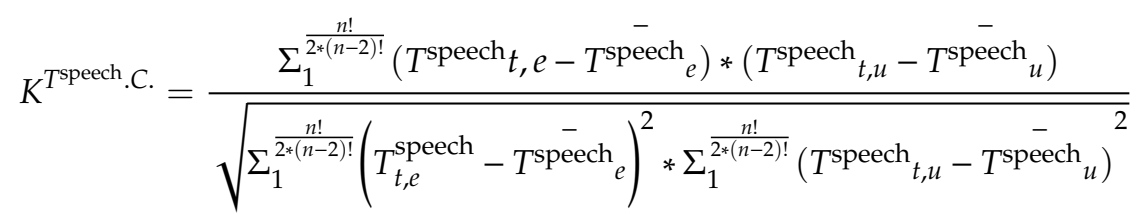

where: $K^{T \text { positive.C }}$ is the coefficient for the tonal compatibility of a work team in the context of the level of positivity of the distributed content; 
$K^{T \text { negative.C }}$ is the coefficient for the tonal compatibility of a work team in the context of the level of negativity of the distributed content;

$K^{T \text { speech.C }}$ is the coefficient for the tonal compatibility of a work team in the context of the level of naturalness of the distributed content;

$n$ is the necessary number of members of the professional team or the number of professional roles in the team;

$T^{\text {positive }}{ }_{t, e}$ is the integral coefficient for the positivity level of the distributed object content $t$ in series $e$;

$T^{\text {negative }}{ }_{t, e}$ is the integral coefficient for the negativity level of the distributed object content $t$ in series $e$;

$T^{\text {speech }_{t, e}}$ is the integral coefficient for the naturalness level of the distributed object content $t$ in series $e$;

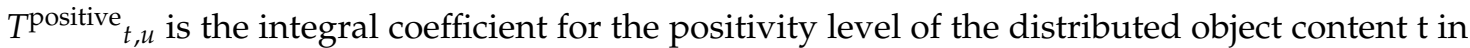
series $u$;

$T^{\text {negative }}$ t,u is the integral coefficient for the negativity level of the distributed object content $t$ in series $u$;

$\mathrm{T}^{\text {speech }} t, u$ is the integral coefficient for the naturalness level of the distributed object content $t$ in series $u$;

$T^{\text {positive }}{ }_{e}$ is the average value of the integral coefficient for the positivity level of the distributed content in series $e$;

$T^{\text {negative }}{ }_{e}$ is the average value of the integral coefficient for the negativity level of the distributed content in series $e$;

$T^{\text {speech }}{ }_{e}$ is the average value of the integral coefficient for the naturalness level of the distributed content in series $e$;

$T^{\text {positive }}{ }_{u}$ is the average value of the integral coefficient for the positivity level of the distributed content in series $u$;

$T^{\text {negative }}{ }_{u}$ is the average value of the integral coefficient for the negativity level of the distributed content in series $u$;

$T^{\text {speech }}{ }_{u}$ is the average value of the integral coefficient for the naturalness level of the distributed content in series $u$.

This coefficient is measured from -1 to 1 , where -1 reflects the maximum opposite of the team in terms of tonal correlation, and 1 , in turn, reflects the ultimate tonal correlation. However, the maximum value of this coefficient is not an optimal value of the compatibility criterion since, at its limit values, the risk of deviating from professional activities and the transition to unearmarked communication grows. According to the Cheddock scale, the minimum level of the correlation coefficient, which reflects a high degree of communication, is the value 0.7. In the framework of the current method, it is suggested to use this value as the most effective, while its deviation to either side is not desirable. Thus, the resulting coefficient for the tonal compatibility of a work team needs to be introduced $\left(R^{T . C}\right.$ ), the distribution of which has the following form (Figure 6).

For the purposes of the most accurate definition of this coefficient according to the actual value of the coefficient for the tonal compatibility of a work team, it is suggested to use a fifth-degree polynomial function.

$$
R^{T . C .}=0.06+0.64 \times K^{T . C .}+1.53 \times\left(K^{T . C .}\right)^{2}+0.41 \times\left(K^{T . C .}\right)^{3}-1.66 \times\left(K^{T . C .}\right)^{4}-1.12 \times K^{\text {T.C. } 5}
$$

The resulting coefficient of the tonal compatibility of a work team is a comparative parameter according to which the comparability of each of the possible invariants of work teams, formed on the basis of combining objects of the initial group, can be characterized when describing the emotional component. The team with the biggest value of this parameter can be considered the most compatible of the entire set of potential combinations of the work team. 


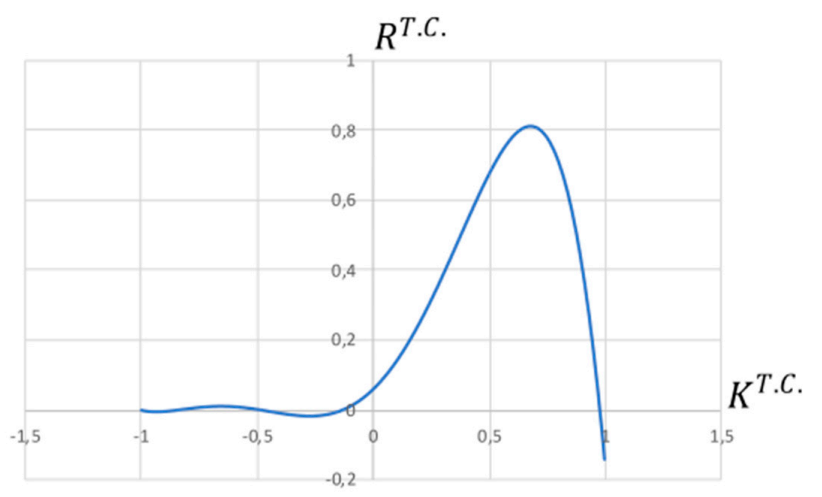

Figure 6. Distribution of the resulting coefficient for the tonal compatibility of a work team.

Next, the content component should be examined, the analytical basis for the determination of which is groups of tokens created based on social profiles. In this case, the content component determines the lexical and partially thematic compatibility of potential members of the work team. This compatibility can be expressed by a weighted assessment of the crossover of token multipliers of each of the potential members of the work team. The specific weight is effectively determined by how often the token is mentioned. Thus, according to the possible binary communication combinations formed earlier, two multipliers of tokens can be determined for each of the combinations:

(1) The total set of tokens, which includes all tokens contained in two groups of tokens of the corresponding social profiles.

(2) A multiplier of intersecting tokens, which includes not tokens found in both groups of tokens of the corresponding social profiles.

The multiplier of intersecting tokens in this case reflects the area of lexical and thematic compatibility of two potential members of a work team. Thus, the weighted share of this multiplier in the total set of tokens reflects the compatibility of two potential members of a work team according to the content component. For each possible grouping of potential members of a work team, the given parameter can be determined according to the following model:

$$
R^{\text {C.C. }}=\frac{\sum_{1}^{\frac{n !}{2 *(n-2) !} \frac{\Sigma_{f_{1}}^{f_{t}} F r_{t}}{\Sigma_{f_{1}}^{f_{x}} r_{x}}}}{\frac{n !}{2 *(n-2) !}}
$$

where: $R^{C . C}$ is the resulting coefficient for the content compatibility of the work team;

$F r_{t}$ is the sum of the frequency of the intersecting token $t$ yof both potential members of the work team;

$F r_{x}$ is the frequency of the $x$ yof the corresponding potential member of the work team;

$f_{t}$ is the number of intersecting tokens;

$f_{x}$ is the total number of tokens mentioned by both potential members of the work team.

This resulting parameter is measured from 0 to 1 , and the increment function of its efficiency is linearly positive, which determines the choice of the most compatible work team according to the maximum value of this parameter.

During the final stage of the examined method, the obtained results are analyzed and the most compatible potential members of the work team are chosen. This choice can be mathematically formalized by introducing the compatibility coefficient of the work team (TC), which is determined as the average arithmetic from the resulting coefficient for the content compatibility of the work team and of the resulting coefficient for the tonal compatibility of the work team. This parameter is measured 
from 0 to 1 , defined for each of the variants of the potential work team. The choice is carried out according to the universal rule of maximizing this parameter.

\section{Discussion}

In his well-known article, Christensen focused on the determinants of open modes of innovation associated with the industrial dynamics of an industry segment undergoing a process of radical technological innovation [38] unraveling the Open Innovation concept which was initially studied by Chesbrough from the company-level perspective (in contrary to the closed innovation old model) and illustrated with cases of large American companies such as IBM, Intel, Lucent, and Xerox.

Some interesting approaches could be discussed, such as "Discussion: Social Profiles" Analysis and Open Innovation" about open innovation dynamics regarding the following main issues:

- Entrepreneurial cyclical dynamics of open innovation;

- Micro- and macrodynamics of open innovation;

- The culture for open innovation dynamics;

- The open innovation journey: how firms dynamically implement emerging innovation management;

- Unraveling the process from closed to open innovation; evidence from mature, asset-intensive industries.

Undoubtedly, the logic of open innovation relates to the nature of collaboration within entrepreneurial ecosystems. We agree with a very interesting point of view of Pustovrh, Rangus, and Drnovšek, assuming that the open innovation paradigm could be useful in analyzing the collaborations among stakeholders within an entrepreneurial ecosystem and supporting the key integrative role of a business accelerator within such a system in open innovation research over the past few years [39]. Open innovation could be treated as the theoretical framework for collaborative innovation in view of the "lean" approach extending from the usual "lean start-up" [40] to methodology to the "lean" entrepreneurship approach in large companies. The collaboration could be considered as the main feature of digital ecosystems [41]. The core idea of this discussion is that social profiles' analysis could improve the contextual environment of open innovations regulating the processes and performance of actors within the entrepreneurial ecosystem. The culture for open innovation considers the collaboration emerging among entrepreneurial actors, organizations, institutions, which formally and informally coalesce to connect, mediate, and govern performance within the local entrepreneurial environment [42].

Innovation teams dealing with the development of solutions based on digital technological innovations are studied in [43]. Unlike previous works, this paper shows that the social profiles' analysis could play a key role in raising the level of communication compatibility while implementing business acceleration programs being the preseed investment, with an emphasis on intensive mentoring, networking, and an educational program for cohorts or classes of start-ups being considered by Miller and Bound [44]. In this regard, in this paper, a fundamentally new approach to creating a potentially efficient work team was proposed. This was used as the basis for the theory put forward by the authors, according to which the level of communication compatibility, reflecting the power of possible communication barriers and acting as the key parameter determining the potential efficiency of a work team. The communication compatibility of a work team was differentiated according to two basic components: the content component, reflecting the lexical and thematic compatibility of the work team; and the tonal component, reflecting the emotional compatibility of the work team. To assess the corresponding components, in relation to the variation of the work team, analytical tools were proposed, the information basis for the application of which is based on information distributed in social networks by potential members of the work team. For each of the proposed tools, a procedure for the implementation and parametric analysis of the obtained results was developed. The total number of tools for finding, collecting, aggregating, processing, assessing, and analyzing the results and creating an objective management solution was aggregated into a single method for creating the most communicatively compatible work team, which is the final result of this study. Implementing 
this method involves excluding the subjectivity of expert decisions, as well as completely automating the assessment process, which fully corresponds to the goal setting of digital ecosystems.

The proposed tool was tested within the framework of the organization of the research team of Peter the Great St. Petersburg Polytechnic University for the purpose of fulfilling the obligations under the grant from the Russian Foundation for Basic Research (RFBR, https://www.rfbr.ru/rffi/eng/info_eng), for a period of three calendar years (Project Number: 20-01400029), entitled "Development of scientific and theoretical foundations creation of logistics networks based on digital platforms."

Within the framework of this grant, the following professional roles in the research team were identified:

(1) Head of the research team. This representative must have experience in successfully leading alternative research projects, and also be a specialist in the field of logistics networks.

(2) Specialist in the field of logistics network modeling.

(3) Specialist in the field of digitalization of business processes.

(4) Specialist in the field of digital programming platforms.

(5) An expert in C\# programming.

(6) Administrative specialist.

From two to five potential participants applied for each of the professional roles, which in total made it possible to form up to 75 potential combinations of the research team. Based on the results of applying the algorithm proposed in this article, a team variant with a resulting TC value of 0.58 points was selected. The value of this indicator can be interpreted as high and is more than $20 \%$ higher than the value of this indicator for alternative teams, which in turn is confirmed by the successful fulfillment of soil obligations. The high level of team compatibility is largely due to joint work experience and relative age compatibility. Therefore, it can be assumed that the level of communication barriers is minimal. As can be seen, the use of the proposed tool made it possible to analyze the invariants of potential groups in detail and form a communicatively optimal one. The effectiveness of this team is confirmed by the successful fulfillment of their obligations for the first year, which is confirmed by the quality of the protected scientific report. Therefore, the proposed tool can be considered successfully tested. However, it is necessary to note several shortcomings of this tool, which were identified during the testing:

(1) Some of the potential team members did not have accounts on social networks, and therefore they had to be excluded from the list of applicants. This problem can be solved by adapting the presented tool for analyzing the universal electronic trace left by every person on the Internet. Any fact of visiting the site, buying something online, or moving around the city with the GPS turned on in the phone is recorded and forms an individual electronic trail of a person, which can also be analyzed. Undoubtedly, ethical problems arise when carrying out this analysis [45], which forms the main problem of the development of the proposed approach.

(2) Information presented by people on social networks may be inaccurate and aimed at forming a conditional digital image [46]. This issue has been researched by many scientists and was considered in great detail for the example of Twitter [47]. The solution to this problem also lies in the transition from the analysis of information in social networks to the analysis of digital metadata.

(3) The proposed tool is primarily aimed at reducing information entropy in the formation of a workforce and, as a consequence, increasing the predictive properties of the results of the work of the team. However, this contradicts the basic principles of dialectics, according to which the conflict provokes the search for the best solution, and, as a consequence, development. In this case, it should be noted that conflicts produced within the framework of incompatible teams can be detached from the main activity, which in turn will reduce the overall efficiency of the team.

The formulated problems are key to the development of the presented tools. It is the solution to these problems that further research of the authors of this article will be devoted to. 


\section{Conclusions}

Within the framework of this study, assessing the participation of employees in social media was confirmed to be important for forming a judgment of their compatibility in the activities of a work team under the influence of the digital platforms, blogs, messages, and social network sites. For the basis, the authors used the four-level communication ecological structure, made up of a technological level (social media), discursive level (content of communication), individual people as an individual level, and the social sphere. The digital management of personnel relies on assessing the role of internal communication of present personnel in social networks, which is related to the interaction of employees through social media technologies in the digital economy.

The goal of the study is to develop an approach for managing personnel based on data obtained from social networks, for example, social profiles of the employees, with the development of a corresponding model to assess the level of communication compatibility, which is an innovative solution in the methodology of digital personnel management.

A method that allows the most compatible work team to be created was proposed based on the automated analysis of information contained in the social profiles of potential members of a work team. Compatibility in this case acts as the optimization criterion due to the fact that even at a high level of professional skill of the work team members, losses in resources are unavoidable when overcoming communication barriers. The significance of these barriers, or the insignificance of these barriers, can be quantitatively reflected thanks to the compatibility parameter proposed by the authors. The compatibility parameter is differentiated into two fundamental components, content and tonal, each of which reflecting specific aspects of the communication compatibility of potential members of the work team (tonal is the emotional compatibility, while content is the lexical and thematic compatibility). Assessing each of these parameters in relation to binary communication combinations of potential members of a work team makes it possible to determine from the total number of potential work team combinations the most compatible according to the criterion of maximizing the resulting parameter. The detailed method for creating the most compatible team based on processing natural information is presented in the figure.

The developed method makes it possible to discard elements of subjectivity when forming the most compatible work team, which significantly reduces the variability of the result and the laboriousness of making management decisions. The created method is a significant addition to the digital ecosystem of a modern company and is useful for specialists in the field of HR, managers of various levels, as well as researchers in the field of personnel management economics.

Author Contributions: Conceptualization, I.A.; data curation, M.D.; formal analysis, E.K.; methodology, S.B.; project administration, O.K.; supervision, V.Y. All authors have read and agreed to the published version of the manuscript.

Funding: This research work was supported by the Academic Excellence Project 5-100 proposed by Peter the Great St. Petersburg Polytechnic University.

Conflicts of Interest: The authors confirm that there are no conflicts of interest to declare for this publication

\section{References}

1. Goos, M.; Konings, J.; Vandeweyer, M. Employment Growth in Europe: The Roles of Innovation, Local Job Multipliers and Institutions. Local Job Mult. Inst. 2015. [CrossRef]

2. de Groen, W.P.; Lenaerts, K.; Bosc, R.; Paquier, F. Impact of Digitalisation and the on-Demand Economy on Labour Markets and the Consequences for Employment and Industrial Relations; European Economic and Social Committee: Bruxelles, Belgium, 2017.

3. Greif, H. Affording illusions? Natural information and the problem of misperception. AVANT 2019, 10, 1-21. [CrossRef]

4. Gera, I.; Singh, S. An Inquiry into the impact of the Fourth Industrial Revolution on Employment: A Review. In Proceedings of the 10th International Conference on Digital Strategies for Organizational Success, Madhya Pradesh, India, 5-7 January 2019. [CrossRef] 
5. Leopold, T.A.; Ratcheva, V.S.; Zahidi, S. The Future of Jobs Report; World Economic Forum: Colony, Switzerland, 2018.

6. Arntz, M.; Gregory, T.; Zierahn, U. The Risk of Automation for Jobs in OECD Countries: A Comparative Analysis; OECD: Paris, France, 2016; Volume 189.

7. Chinoracký, R.; Čorejová, T. Impact of digital technologies on labor market and the transport sector. Transp. Res. Procedia 2019, 40, 994-1001. [CrossRef]

8. Novakova, L. The impact of technology development on the future of the labour market in the Slovak Republic. Technol. Soc. 2020, 62, 101256. [CrossRef]

9. Abramova, N.; Grishchenko, N. ICTs, Labour Productivity and Employment: Sustainability in Industries in Russia. Procedia Manuf. 2020, 43, 299-305. [CrossRef]

10. Autor, D.H. Why are there still so many jobs? the history and future of workplace automation. J. Econ. Perspect. 2015, 29, 3-30. [CrossRef]

11. Katz, R.L. Social and Economic Impact of Digital Transformation on the Economy; GSR-17 Discussion paper; International Telecommunication Union (ITU): Geneva, Switzerland, 2017; pp. 4-41.

12. Yaslan, Y.; Gülaçar, H.; Koç, M.N. User Profile Analysis Using an Online Social Network Integrated Quiz Game. J. Nat. Appl. Sci. 2017, 21, 696. [CrossRef]

13. Fossen, F.; Sorgner, A. Mapping the Future of Occupations: Transformative and Destructive Effects of New Digital Technologies on Jobs. Foresight STI Gov. 2019, 13, 10-18. [CrossRef]

14. Zhang, L.; Guo, X.; Lei, Z.; Lim, M.K. Social network analysis of sustainable human resource management from the employee training's perspective. Sustainability 2019, 11, 380. [CrossRef]

15. Ojelabi, R.; Oyeyipo, O.; Afolabi, A.; Amusan, L. Presence of social client relationship management within the Nigerian construction industry. Buildings 2018, 8, 60. [CrossRef]

16. Mishra, K.; Boynton, L.; Mishra, A. Driving employee engagement: The Expanded Role of Internal Communications. Int. J. Bus. Commun. 2004, 51, 183-202. [CrossRef]

17. Haddud, A.; Dugger, J.C.; Gill, P. Social Media for Organizations Exploring the Impact of Internal Social Media Usage on Employee Engagement Journal of Social Media for Organizations Exploring the Impact of Internal Social Media Usage on Employee Engagement. J. Soc. Media Organ. 2016, 3, 1.

18. Cao, X.; Guo, X.; Vogel, D.; Zhang, X. Exploring the influence of social media on employee work performance. Internet Res. 2016, 26, 529-545. [CrossRef]

19. Çetinkaya, A.Ş.; Rashid, M. The Effect of Use of Social Media on Employee job Performance. J. Internet Appl. Manag. 2018, 9, 5-20. [CrossRef]

20. Badea, M. Social Media and Organizational Communication. Procedia-Soc. Behav. Sci. 2014, 149, 70-75. [CrossRef]

21. IBM. Amplifying Employee Voice: How organizations Can Better Connect to the Pulse of the Workforce; IBM: Armonk, NY, USA, 2015.

22. Macnamara, J.; Zerfass, A. Social Media Communication in Organizations: The Challenges of Balancing Openness, Strategy, and Management. Int. J. Strateg. Commun. 2012, 6, 287-308. [CrossRef]

23. Omar, M.K.; Dahalan, N.A.; Yusoff, Y.H.M. Social Media Usage, Perceived Team-Efficacy and Knowledge Sharing Behaviour among Employees of an Oil and Gas Organisation in Malaysia. Procedia Econ. Financ. 2016, 37, 309-316. [CrossRef]

24. Nedbal, D.; Auinger, A.; Hochmeier, A. Addressing Transparency, Communication and Participation in Enterprise 2.0 Projects. Procedia Technol. 2013, 9, 676-686. [CrossRef]

25. Georgescu, M.; Popescul, D. Social Media-The New Paradigm of Collaboration and Communication for Business Environment. Procedia Econ. Financ. 2015, 20, 277-282. [CrossRef]

26. Wong, L.H.M.; Ou, C.X.; Davison, R.M.; Zhu, H.; Zhang, C. Web 2.0 and Communication Processes at Work: Evidence From China. IEEE Trans. Prof. Commun. 2016, 59, 230-244. [CrossRef]

27. Men, L.R. The internal communication role of the chief executive officer: Communication channels, style, and effectiveness. Public Relat. Rev. 2015, 41, 461-471. [CrossRef]

28. Ewing, M.; Men, L.R.; O’Neil, J. Using Social Media to Engage Employees: Insights from Internal Communication Managers. Int. J. Strateg. Commun. 2019, 13, 110-132. [CrossRef]

29. Cardon, P.W.; Marshall, B. The hype and reality of social media use for work collaboration and team communication. Int. J. Bus. Commun. 2015, 52, 273-293. [CrossRef] 
30. Luo, N.; Guo, X.; Lu, B.; Chen, G. Can non-work-related social media use benefit the company? A study on corporate blogging and affective organizational commitment. Comput. Hum. Behav. 2018, 81, 84-92. [CrossRef]

31. Lu, B.; Guo, X.; Luo, N.; Chen, G. Corporate blogging and job performance: Effects of work-related and nonwork-related participation. J. Manag. Inf. Syst. 2015, 32, 285-314. [CrossRef]

32. Sarhadi, M. Comparing Communication Style within Project Teams of three Project-oriented Organizations in Iran. Procedia-Soc. Behav. Sci. 2016, 226, 226-235. [CrossRef]

33. Palme, J. The SQAP Data Base for Natural Language Information. Am. J. Comput. Linguist. 1975, 79, C8376-M3.

34. Palme, J.; Karlgren, J.; Pargman, D. Issues when designing filters in messaging systems. Comput. Commun. 1996, 19, 95-101. [CrossRef]

35. Ngai, E.W.T.; Tao, S.S.C.; Moon, K.K.L. Social media research: Theories, constructs, and conceptual frameworks. Int. J. Inf. Manag. 2015, 35, 33-44. [CrossRef]

36. Hirschberg, J.; Manning, C.D. Advances in natural language processing. Science 2015, 349, 261-266. [CrossRef]

37. Salthe, S.N. Naturalizing Information. Information 2011, 2, 417-425. [CrossRef]

38. Christensen, J.F.; Olesen, M.H.; Kjær, J.S. The industrial dynamics of Open Innovation—Evidence from the transformation of consumer electronics. Res. Policy 2005, 34, 1533-1549. [CrossRef]

39. Pustovrh, A.; Rangus, K.; Drnovšek, M. The role of open innovation in developing an entrepreneurial support ecosystem. Technol. Soc. Chang. 2020, 152. [CrossRef]

40. Blank, S. Why the lean start-up changes everything. Harv. Bus. Rev. 2013, 91, 63-72.

41. Barykin, S.Y.; Kapustina, I.V.; Kirillova, T.V.; Yadykin, V.K.; Konnikov, Y.A. Economics of Digital Ecosystems. J. Open Innov. Technol. Mark. Complex. 2020, 6, 124. [CrossRef]

42. Brown, R.; Mason, C. Looking inside the spiky bits: A critical review and conceptualisation of entrepreneurial ecosystems. Small Bus. Econ. 2017, 49, 11-30. [CrossRef]

43. Hadjielias, E.; (Lola) Dada, O.; Discua Cruz, A.; Zekas, S.; Christofi, M.; Sakka, G. How do digital innovation teams function? Understanding the team cognition-process nexus within the context of digital transformation. J. Bus. Res. 2021, 122, 373-386. [CrossRef]

44. Miller, P.; Bound, K. The Rise of Accelerator Programmes to Support New Technology Ventures; NESTA: London, UK, 2011.

45. Pan, B.; Crotts, J.C. Theoretical models of social media, marketing implications, and future research directions. In Social Media in Travel, Tourism and Hospitality: Theory, Practice and Cases; Sigala, M., Christou, E., Gretzel, U., Eds.; Ashgate Publishing Ltd.: Surrey, UK, 2012; pp. 73-86. ISBN 0018439535697.

46. Chen, Y.; Wang, Q.I.; Xie, J. Online social interactions: A natural experiment on word of mouth versus observational learning. J. Mark. Res. 2010, 48, 238-254. [CrossRef]

47. Bollen, J.; Mao, H.; Zeng, X. Twitter mood predicts the stock market. J. Comput. Sci. 2011, 2, 1-8. [CrossRef]

Publisher's Note: MDPI stays neutral with regard to jurisdictional claims in published maps and institutional affiliations.

(C) 2020 by the authors. Licensee MDPI, Basel, Switzerland. This article is an open access article distributed under the terms and conditions of the Creative Commons Attribution (CC BY) license (http://creativecommons.org/licenses/by/4.0/). 